\title{
Pigmentary keratitis in pugs in the United Kingdom: prevalence and associated features
}

\author{
S. Maini ${ }^{1 *} \mathbb{D}$, R. Everson ${ }^{2}$, C. Dawson ${ }^{3}$, Y. M. Chang ${ }^{4}$, C. Hartley ${ }^{1}$ and R. F. Sanchez ${ }^{5}$
}

\begin{abstract}
Background: Pigmentary keratitis (PK) is commonly recognised in Pugs, but its aetiology is not completely understood. The aim of this study was to determine the prevalence and associated features of PK in Pugs in the United Kingdom (UK).

Results: A total of 210 Pugs (420 eyes) were recruited from 12 UK dog shows and social events. The median age of Pugs recruited was 2.50 years (range $0.25-16.25$ years). Pigmentary keratitis was detected in 369/420 (87.8\%) eyes and in at least one eye 193/210 (91.9\%) Pugs, of which 17/193 (8.8\%) were affected unilaterally and 176/193 (91.2\%) bilaterally. Pigmentary keratitis was typically mild to moderate ( 46.3 and $49.9 \%$ of eyes, respectively). Detection of PK was significantly associated with increased age $(P=0.002)$ and the presence of medial entropion of the lower eyelid (MELE) $(P=0.001)$. Severity of PK was significantly associated with the grade of MELE $(P<0.001)$. There was also a correlation between the presence of limbal pigment and PK $(P=0.036)$ that warrants further study.

Conclusions: This study estimated a high disease prevalence of PK in UK Pugs, and demonstrated significant associations with age and the presence of MELE. These associations, which have not been previously reported, offer an insight into the underlying pathophysiology of this condition in Pugs. The results encourage further population research, such as prospective longitudinal studies. These findings also support the development of clinical and breeding strategies based on the reduction of MELE and, possibly, limbal pigment.
\end{abstract}

Keywords: Entropion, Brachycephalic, Canine, Cornea, Pigment, Keratitis, Corneal pigmentation, Medial entropion

\section{Background}

Pigmentary keratitis is a term used to describe the development of corneal pigmentation associated with chronic inflammation [1]. If PK encroaches upon the visual axis, it can cause significant visual impairment and, in severe cases, blindness [2,3]. Pigmentary keratitis occurs due to centripetal migration of melanocytes from the limbal and perilimbal region and subsequent deposition of melanocytic pigment within the corneal epithelium and anterior stroma [1,3-6]. Corneal pigmentation is also frequently reported as a feature of inflammatory corneal pathology, such as keratoconjunctivitis sicca (KCS), chronic superficial keratitis (pannus) and chronic, ulcerative/nonulcerative keratitis [2, 7-12]. Pigmentary

\footnotetext{
* Correspondence: serenamaini@hotmail.com

'Langford Veterinary Services, University of Bristol, Langford, Bristol, UK

Full list of author information is available at the end of the article
}

keratitis appears to develop more rapidly and readily in some brachycephalic breeds and it has been shown to be widespread within the Pug breed in two studies based in the United States of America (USA) and one study from Austria, that reported estimated prevalence rates of 82.4, 71.8 and $70 \%$, respectively $[1,11,13]$. Reputed causative or contributory factors of PK in Pugs include chronic irritation from distichiasis, nasal fold trichiasis, medial entropion, and macroblepharon [14, 15]; however, supporting evidence for their influence on the development of PK has so far proven elusive [11, 13]. Additional suggestions have been made of possible primary components in the development of PK in the Pug breed, such as a limbal stem cell deficiency or genetic factors $[13,16$, 17]. Pugs are a popular breed in the UK, with the number of Pugs registered with the UK Kennel Club (KC) having doubled between 2009 and 2015; figures plateaued at approximately 10,000 Pugs per year between 2014 and 2018.

(c) The Author(s). 2019 Open Access This article is distributed under the terms of the Creative Commons Attribution 4.0 International License (http://creativecommons.org/licenses/by/4.0/), which permits unrestricted use, distribution, and reproduction in any medium, provided you give appropriate credit to the original author(s) and the source, provide a link to the Creative Commons license, and indicate if changes were made. The Creative Commons Public Domain Dedication waiver (http://creativecommons.org/publicdomain/zero/1.0/) applies to the data made available in this article, unless otherwise stated. 
The aim of this study was to contribute to the body of research on this poorly understood but widespread condition by estimating the prevalence of PK in Pugs in the UK, and determining if there were any statistical associations with ocular, adnexal or facial features.

\section{Results}

\section{Study population}

Two hundred and ten dogs, with a total of 420 eyes, were included in the study. Individuals were recruited from one of 12 national events and, collectively, represented a large area of the UK (Fig. 1). Sex, neuter status, age, coat colour, UK KC registration and show status were as follows for those dogs where this information was provided/recorded. Sex was known for 208/210 (99.0\%) dogs; the sample population included 120/208 (57.7\%) females and 88/208 (42.3\%) males. Neuter status was provided for 206/210 (98.1\%) dogs; a total of 66/206 (32.0\%) dogs were neutered and 140/206 (68.0\%) were entire. Age was known for 203/210 (96.7\%) Pugs; the

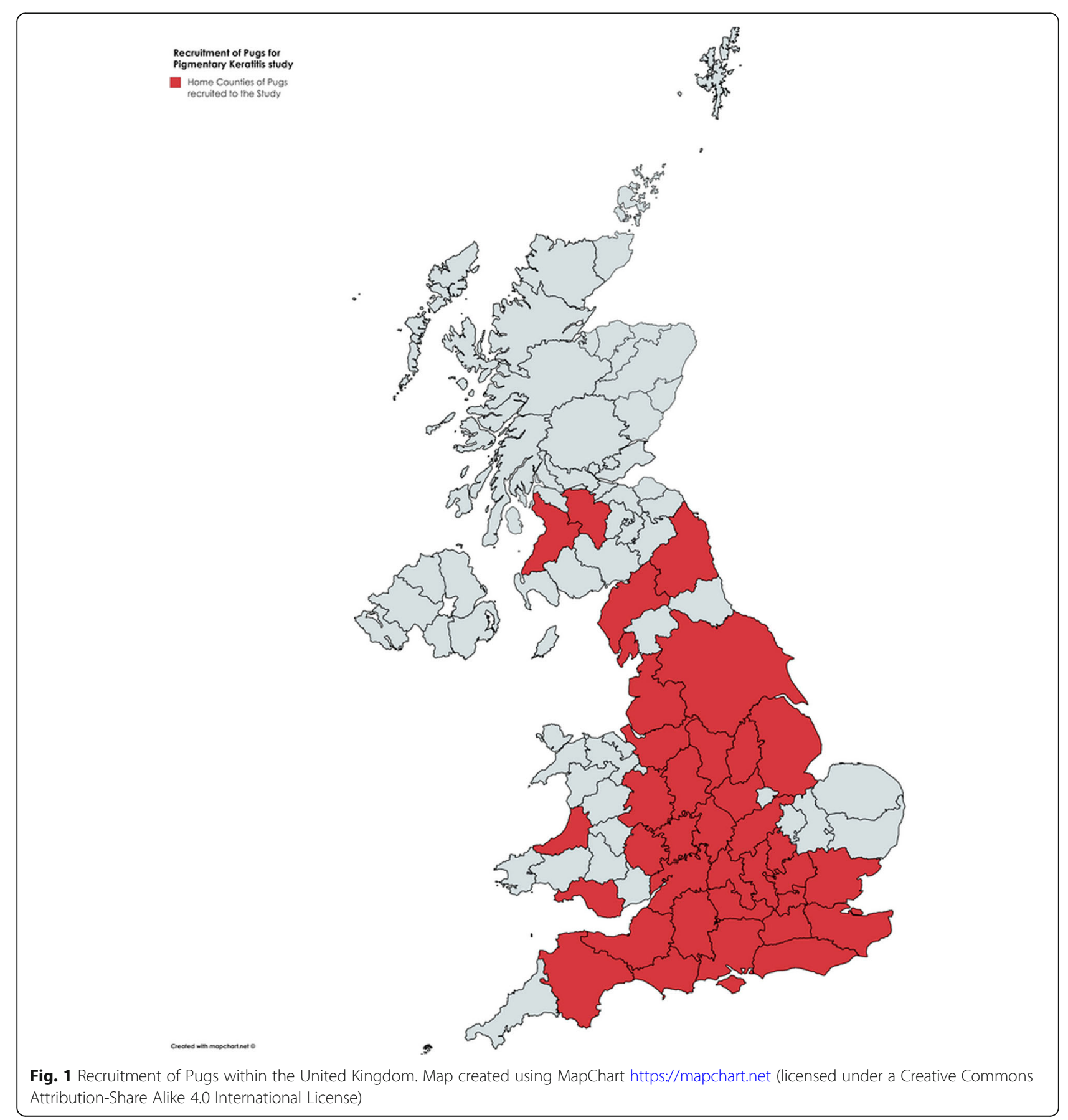


median age was 2.50 years (interquartile range 2.92 years, range $0.25-16.25$ years). Coat colour was recorded for 207/210 (98.6\%) cases. Colour variations were categorised into three groups: fawn $(146 / 207 ; 70.5 \%)$, black (50/207; 24.2\%) and other (11/207; 5.3\%). Most dogs for whom registration status was provided $(173 / 210 ; 82.4 \%)$ were registered with the UK KC (158/173; 91.3\%); 15/ $173(8.7 \%)$ were not registered. Show status was provided for 131/210 (62.4\%) dogs; a total of 81/131 (61.8\%) were described as 'show dogs' and 50/131 (38.2\%) were not routinely entered into shows.

General ocular, adnexal and facial features (excluding PK) Features that were not associated with PK detection or severity included medial entropion of the upper eyelid (MEUE), craniofacial index (CFI), over-nose-wrinkle (ONW), nasal fold width, palpebral fissure length, iristo-iris persistent pupillary membranes (IIPPMs) and distichia (Table 1). MELE, which was associated with PK severity, could be assessed in 374/420 (89.0\%) eyes. A total of 352/374 (94.1\%) eyes exhibited MELE and 22/ 374 (5.9\%) did not. Of the 374 eyes that were assessed, 276/374 (73.8\%) were categorised as grade 1 MELE and $76 / 374(20.3 \%)$ as grade 2; and comprised 78.4 and $21.6 \%$ of the eyes with MELE, respectively. Length (i.e. \%) of lower eyelid affected by MELE ranged from $0.0-50.0 \%$, with a mean $(+/-s d)$ of $22.4(+/-9.9) \%$. IIPPMs were detected in 198/420 (47.1\%) eyes and were not detected in $222 / 420(52.9 \%)$ eyes; they were detected in at least one eye of $117 / 210$ (55.7\%) dogs, leaving 93/210 (44.3\%) that were unaffected. Distichiasis was detected in 30/420 (7.1\%) eyes and was not detected in 390/420 (92.9\%) eyes. At least one eye of $25 / 210$ (11.9\%) dogs was affected by distichiasis, with most dogs being unaffected (185/210; $88.1 \%)$. A total of $170 / 210(81.0 \%)$ dogs were examined to see if they had an ONW; an ONW was present in 59/170 (34.7\%) dogs and was absent in 111/170 (65.3\%) dogs. Medial entropion of the upper eyelid was present in 28/ 410 (6.7\%) eyes. Craniofacial index was assessed in 206/ 210 (98.1\%) dogs; values ranged from 0.05 to 0.33 , with a mean of $0.18(+/-0.04)$. Nasal fold width was assessed in $399 / 410$ (95.0\%) eyes; values ranged from 1.0 to $24.0 \mathrm{~mm}$, with a mean of $5.83(+/-2.06) \mathrm{mm}$. Palpebral fissure length was measured in $363 / 410$ (86.4\%) eyes; values ranged from 18.0 to $30.0 \mathrm{~mm}$, with a mean of $23.96(+/-$ 2.17) $\mathrm{mm}$. All Pugs in this study (420/420 eyes) had a Schirmer tear test 1 (STT1) test performed to rule out with certainty that there was no KCS; measurements ranged from 15.0 to $33.0 \mathrm{~mm} / \mathrm{min}$ of wetting, with a mean of $21.10(+/-3.24) \mathrm{mm} / \mathrm{min}$. A total of $102 / 420$ eyes had STT1 readings for less than $1 \mathrm{~min}(15-35 \mathrm{~s}) ; 94 / 102$ had STT1 readings of at least $30 \mathrm{~s}$. All 102 eyes were included in the study as they measured at or above $15 \mathrm{~mm}$ of wetting.
Table 1 Univariable analysis of detection and severity of PK and association with predictors

\begin{tabular}{|c|c|c|}
\hline \multirow[t]{2}{*}{ Predictor } & Detection of PK & Severity of PK \\
\hline & OR $(95 \% \mathrm{Cl}), P$ & OR $(95 \% \mathrm{Cl}), P$ \\
\hline Age (per year) & $1.53(1.16-2.00), 0.002$ & $1.08(0.98-1.20), 0.132$ \\
\hline Sex (male vs. female) & $1.44(0.66-3.15), 0.362$ & $0.96(0.59-1.56), 0.878$ \\
\hline $\begin{array}{l}\text { Neuter status } \\
\text { (neutered vs. entire) }\end{array}$ & $0.70(0.31-1.52), 0.355$ & $1.02(0.60-1.73), 0.947$ \\
\hline $\begin{array}{l}\text { KC registration } \\
\text { (registered vs. no) }\end{array}$ & $1.20(0.32-4.53), 0.792$ & $0.84(0.31-2.32), 0.738$ \\
\hline $\begin{array}{l}\text { Show dog status } \\
\text { (yes vs. no) }\end{array}$ & $0.50(0.18-1.40), 0.188$ & $0.63(0.34-1.2), 0.162$ \\
\hline STT1 measurement & $1.00(0.93-1.07), 0.919$ & $0.98(0.92-1.05), 0.573$ \\
\hline Limbal pigmentation & $0.95(0.87-1.04), 0.277$ & $1.04(0.98-1.11), 0.183$ \\
\hline \multicolumn{3}{|l|}{ MELE (grade) } \\
\hline $\begin{array}{l}\text { Grade } 1 \text { vs. MELE } \\
\text { not present }\end{array}$ & 6.31 (2.18-18.26), 0.001 & $0.62(0.21-1.81), 0.380$ \\
\hline $\begin{array}{l}\text { Grade } 2 \text { vs. MELE } \\
\text { not present }\end{array}$ & $\begin{array}{l}13.97(3.44-56.81) \\
<0.001\end{array}$ & $1.94(0.59-6.41), 0.279$ \\
\hline $\begin{array}{l}\text { Grade MELE not } \\
\text { present vs. } 2\end{array}$ & $0.07(0.02-0.29),<0.001$ & $0.52(0.16-1.71), 0.279$ \\
\hline $\begin{array}{l}\text { Grade } 1 \text { vs. } \\
\text { Grade } 2\end{array}$ & $0.45(0.17-1.20), 0.112$ & $0.32(0.18-0.58),<0.001$ \\
\hline MELE (\% length) & $1.02(0.98-1.06), 0.279$ & $1.02(0.99-1.04), 0.135$ \\
\hline MEUE (\% length) & $1.01(0.97-1.05), 0.694$ & $1.02(0.99-1.04), 0.168$ \\
\hline CFI $(<0.18$ vs $\geq 0.18)$ & $1.45(0 .-3.27), 0.370$ & $0.91(0.55-1.49), 0.707$ \\
\hline ONW (yes vs no) & $1.75(0.60-5.07), 0.306$ & $1.27(0.74-2.16), 0.386$ \\
\hline $\begin{array}{l}\text { Nasal fold width } \\
\text { (per mm) }\end{array}$ & $1.27(1.03-1.56), 0.023$ & $1.07(0.88-1.30), 0.482$ \\
\hline $\begin{array}{l}\text { Palpebral fissure } \\
\text { length (per mm) }\end{array}$ & $1.08(0.92-1.27), 0.343$ & $1.08(0.95-1.21), 0.235$ \\
\hline $\begin{array}{l}\text { IIPPMs (presence } \\
\text { vs absence) }\end{array}$ & $0.69(0.39-1.22), 0.206$ & $0.96(0.63-1.46), 0.853$ \\
\hline $\begin{array}{l}\text { Distichia (presence } \\
\text { vs absence) }\end{array}$ & $0.49(0.23-1.06), 0.069$ & $1.22(0.61-2.44), 0.580$ \\
\hline
\end{tabular}

Pigmentary keratitis - descriptive statistics

Pigmentary keratitis was detected in at least one eye of 193/210 (91.9\%) dogs. Seventeen out of 193 (8.8\%) had unilateral PK and 176/193 (91.2\%) exhibited bilateral PK. A total of $369 / 420$ (87.9\%) eyes were affected by PK. Of those affected eyes, $171 / 369(46.3 \%)$ were classified as mild, $184 / 369$ (49.9\%) as moderate, and 14/369 (3.8\%) as severe.

\section{Pigmentary keratitis - detection}

Detection of PK was not significantly associated with signalment, breed club registration, ophthalmic, or any of the adnexal and facial predictors other than age and MELE (Table 1) in the univariable analysis. There was insufficient data to assess coat colour as a predictor for PK detection. Both age (OR $=1.76,95 \%$ CI 1.31-2.36, $P<$ 0.001 ) and presence of MELE (grade 1 vs $0:$ OR $=9.98$, 
95\%CI 3.12-31.94, $P<0.0001$; grade 2 vs $0: \mathrm{OR}=13.19$, $95 \%$ CI 3.30-52.76, $P<0.001)$ remained significant in the multivariable analysis. No significant interaction between MELE and age on PK detection was observed $(P=0.09)$.

\section{Pigmentary keratitis - severity}

Due to the relatively low number of severe cases, the moderate and severe groups were amalgamated to create a combined moderate/severe group, for the purposes of repeated measures logistic regression analysis (mild vs. moderate/severe). Severity of PK was not associated with signalment, breed club registration, or any of the ophthalmic, adnexal or facial predictors other than MELE (Table 1). Increasing PK severity was significantly associated with higher grade MELE (OR $=0.32$, 95\% CI: $0.18-$ $0.58, P<0.001$, when comparing grade 1 to grade 2$)$. No significant interaction between MELE and limbal pigmentation on PK severity was observed $(P=0.666)$.

As an association of PK with limbal pigment was not found $(P=0.183)$, the authors included an additional group of 16 Pugs from outside the study population to test if a larger population would help increase statistical power of this calculation, enough to find statistical significance; the results showed that the inclusion of the additional cases offered enough statistical power to demonstrate a statistically significant association between the severity of PK and increased limbal pigmentation (OR = 1.07, 95\% CI: $1.00-1.15, P=0.036)$ in the multivariable analysis.

\section{Discussion}

This study suggests there is a high prevalence of PK in Pugs living within the UK. The authors selected a representative sample of the national population by attending a wide variety of breed shows and social events. The prevalence of $\mathrm{PK}$ within the sample population was higher than reported in similar studies performed in the USA and Austria $[1,11,13]$. This may reflect differences in population, breeding patterns, genetic background, previous veterinary attention or other as yet unknown factors.

The significant association of PK with the presence of MELE and its severity is, to the authors' knowledge, the first report confirming an association between PK in Pugs and this conformational abnormality, which has long been suspected to be a contributory factor in this disease. This is in contrast with a previous study, which did not demonstrate a statistically significant influence of MELE on PK in Pugs [13]. This disparity may be attributed to differences in population and/or in study design, or to type I or II statistical errors. It is interesting to view the results of the present study in the context of a recent publication which demonstrated microscopic inflammatory changes within corneas affected by PK [1].
The significant associations between PK and MELE found in the current study could be explained by the irritative effect of MELE on the medial cornea of Pugs. This study also found that PK was significantly associated with increased age. The association with age was not entirely surprising as, clinically, PK is known to progress over time [16]. It seems logical to conclude that if corneas with PK have inflammatory changes [1] and if severe entropion is associated with PK (which worsens with age), that surgical correction of severe MELE would have a positive effect on the long-term corneal health of affected Pugs. It would also seem logical to consider the development of breeding strategies that focus on reducing the presence of severe MELE in Pugs. A large-scale prospective cohort study tracking the progression of PK in the presence of MELE, and in Pugs that have undergone surgical MELE correction would undoubtedly further clarify the impact of the associated features identified in the present study. Early, prototype studies have hinted that the correction of MELE, possibly with additional medical therapy, is an area of interest for further research $[9,18,19]$. However, until the results of future investigative studies are available, owners of Pugs with PK and severe MELE should be informed of the associations found to date, as they may wish to consider options that decrease ocular surface inflammation, such as surgical MELE correction.

When the authors realized that an association of PK with limbal pigment was not present, they included a group of 16 dogs from outside the study population solely to test if a larger population would help increase statistical power of this calculation. In doing so the authors found there was indeed a statistically significant association between the severity of PK and increased limbal pigmentation, which was not entirely surprising. This additional group could not be included in the larger analysis because they did not have an STT1 measured and therefore KCS could not be ruled out as the cause of PK. Pigmentary keratitis in Pugs is associated with the presence of MELE, as shown in the present study, but it can also be associated with KCS [11]. It seems logical to suspect an association between PK and the presence of limbal pigment in Pugs in the absence of KCS. However, the statistical strength of this association warrants further study if we are to determine how important the presence of limbal pigmentation is as a risk factor for the development of PK in Pugs. This study demonstrates that the population size needs to be large and offers the approximate number of Pugs needed with a normal STT1 reading and a clinical history free of KCS.

Previous population studies of Pugs reported on the presence of distichiasis as well as IIPPMs and CFI [11, 13, 20]. The present study corroborates the results of those papers in which no significant association between 
distichiasis and PK in Pugs was found [11, 13]. With regards to IIPPMs, one study reported a prevalence of $83.8 \%$ in the left eye and $85.3 \%$ in the right eye [13], while another study reported a much lower prevalence of $8.46 \%$ [11]. The prevalence of IIPPMs in this study was between the two previously published results. A variance in prevalence rates may be due to population differences, as each of the three studies was performed in a different country. The mean CFI of the Pugs included in the current study was higher than in a previous paper, which reported a CFI of $0.08(+/-0.01)$ [20]. Again, this could reflect differences between populations although it is possible that the presence of a large nasal fold hindered the accurate measurement of muzzle length in some cases, which may account in part for the difference between the two studies.

A limbal stem cell deficiency has been proposed as a possible cause of PK in Pugs [13, 17]. A confocal microscopy study of PK-affected Pug corneas supported the role of inflammation as opposed to a limbal stem cell deficiency [1]. However, the authors of that paper agreed that further studies were required to definitively rule out a possible role of stem cell deficiency in Pugs with PK [1]. Microscopic evaluation of affected Pug corneas to prove or disprove this theory was well beyond the scope of the present study. Genetic analysis has also been suggested as a potentially rewarding area of research [13]. However, due to the low number of unaffected Pugs (i.e. controls) identified in the present study, genetic analysis would appear to be challenging to pursue in the UK population.

Limitations of this study include failure to reach the ideal sample size as proposed by power analysis. Additionally, there was a low number of unaffected dogs. To compound this, all unaffected individuals were less than 5 years of age, likely because a large proportion of Pugs were recruited from shows. This has two important implications: a) the importance of this condition in the Pug population may be underestimated and $b$ ) it is unknown if young, unaffected dogs will remain free of PK throughout their lives. It is possible that the inclusion of Pugs that had previously had ulcerative keratitis might have had an impact on the estimated prevalence, as corneal pigmentation is known to develop secondary to chronic inflammation [2, 4, 7-12, 21], and Pugs have been shown to exhibit a high prevalence of corneal ulceration [22]. However, PK in Pugs starts classically in the medial cornea and has a centripetal progression in the shape of a triangle or wedge $[3,13]$ and, in the authors' experience, corneal ulceration has a tendency to lead to a less predictable pigmentation pattern, as amorphous pigmented or non-pigmented scars tend to develop in the spot where a cornea was ulcerated. Yet, distinguishing between the two might not be possible and this is a potential problem of every PK study of Pugs. Even the exclusion of dogs with previously known ulcerative keratitis might not necessarily remove all cases that have had ulcerative keratitis because a small ulcer might go unnoticed by the owner, heal and scar. The examiners of this study made every effort to distinguish between the two presentations although it is acknowledged that the PK data collected might have been affected by pigmentation caused by previous ulceration.

\section{Conclusions}

The prevalence of PK in UK Pugs in this study population was very high. Pigmentary keratitis was more likely to be detected in older Pugs and in those with limbal pigmentation and MELE, especially if MELE was severe. The results of this study offer an insight into the underlying pathophysiology of PK in Pugs and encourage further population research, such as prospective longitudinal studies, to further inform these findings. Moreover, these results support the development of clinical and breeding strategies on the reduction of MELE and limbal pigment.

\section{Methods}

\section{Study design}

A cross-sectional study design was selected, with the following objectives: to estimate prevalence and report descriptive statistics, and to investigate the presence or absence of statistical associations with suspected risk factors.

\section{Study population and methods}

All study methods were approved by the Royal Veterinary College (UK) Ethics \& Welfare Committee. Informed, written consent was obtained from all participating owners. Pugs were enrolled and examined at one of 12 events (three breed club dog shows and nine social events e.g. 'Pug parties', dog charity 'garden parties', breeder/ owner social gatherings) in nine different counties across the UK (East Sussex, Northamptonshire, Lincolnshire, Cheshire, Hertfordshire, London, Wiltshire, Gloucestershire and South Yorkshire) between July 2014 and October 2017. All Pugs that were presented to the examiner at these events were enrolled to the study, unless they had already been examined at a prior event. Pugs with a history of KCS were excluded from the study due to the documented link between KCS and corneal pigmentation $[8,11]$. Signalment and ophthalmic history were obtained from owners by use of owner-completed questionnaires prior to examination. Examinations were performed free of charge and comprised slit-lamp biomicroscopy of ocular adnexa and the anterior segment, STT1, and ocular and facial morphometrics. An examination form (Additional file 1) was used to record 


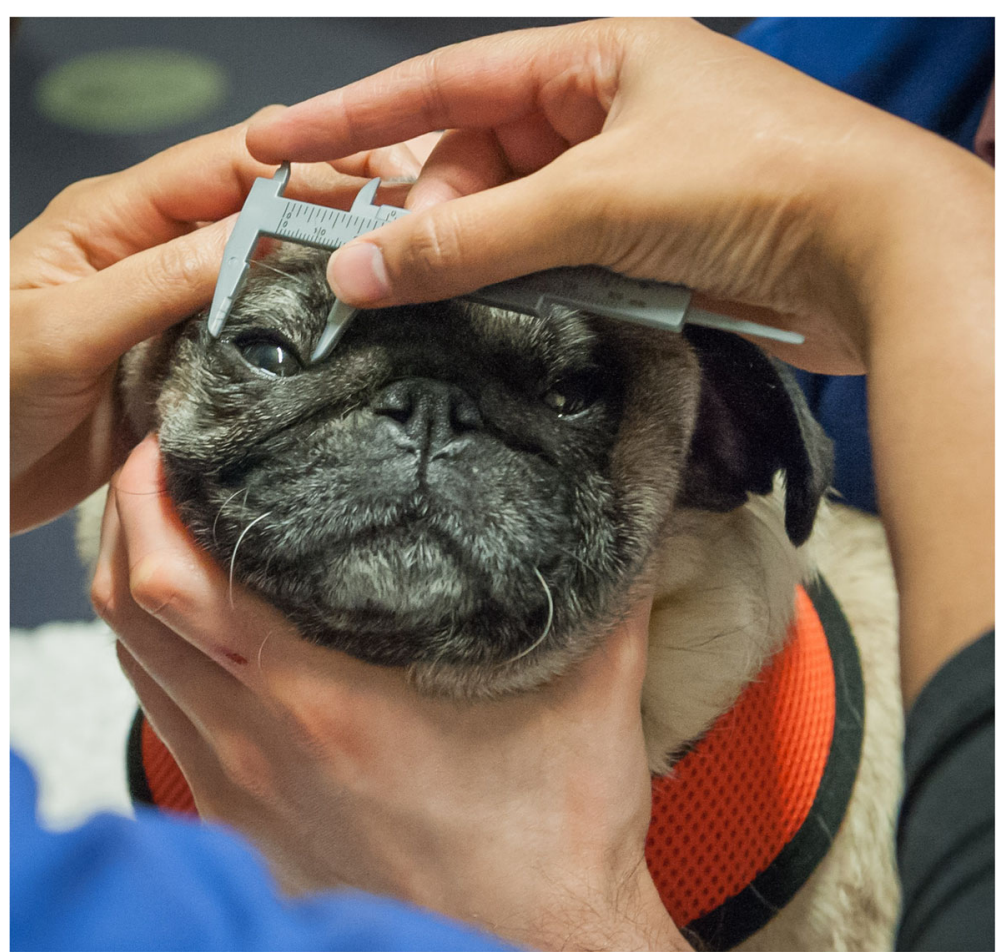

Fig. 2 Measurement of unstretched palpebral fissure width with a blunt-ended Jameson caliper

examination findings. Ocular and facial measurements were collected using previously defined measuring protocols [23]. Craniofacial index was then calculated and used as a measure of brachycephaly [20]. The presence or absence of an ONW, MELE and MEUE were recorded. Additionally, unstretched palpebral fissure width (i.e. distance in millimetres between medial and lateral canthus), was measured using a blunt-ended Jameson caliper (Fig. 2), as was the nasal fold width (i.e. width in millimetres of nasal fold skin that could be grasped by the caliper). Ophthalmic examination was performed by one of two board-certified veterinary ophthalmologists (RFS \&

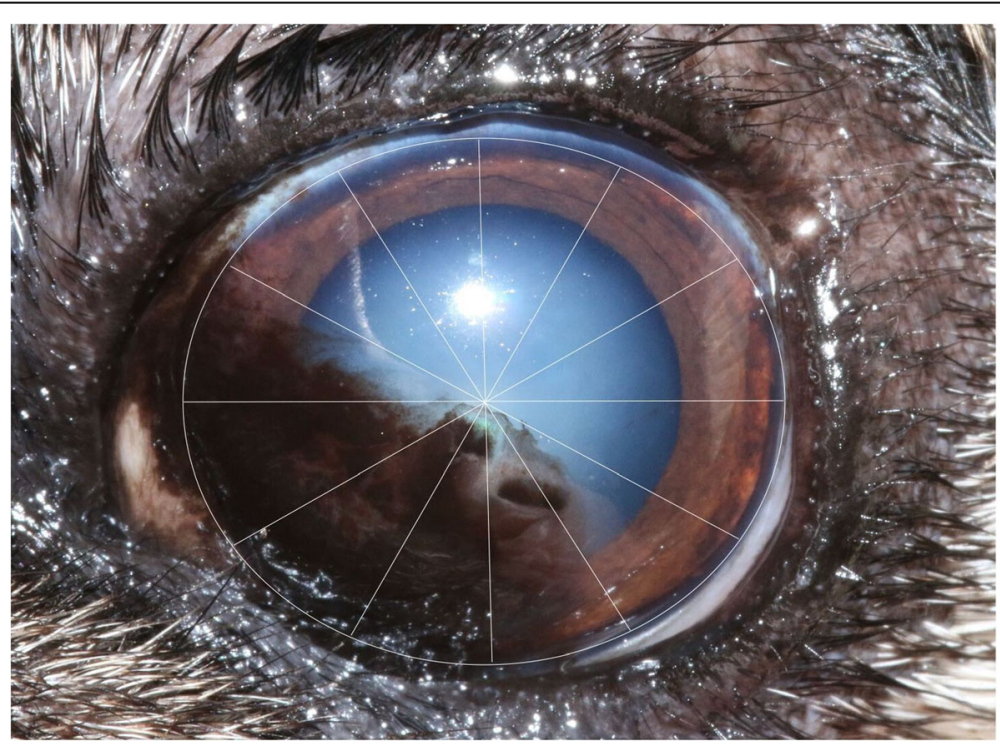

Fig. 3 Assessment of corneal 'clock hours'. Six clock hours were affected by corneal pigmentation (6 points). Two additional points were allocated as the pigment extended beyond the resting pupil edge. Total $=8$ points 


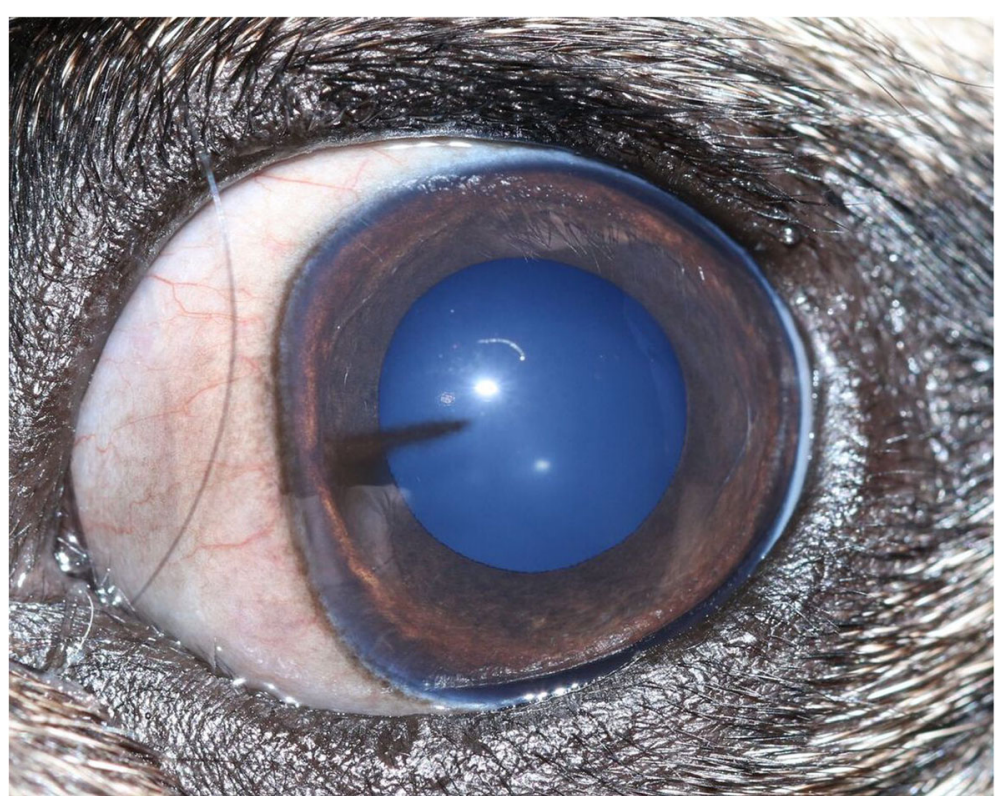

Fig. 4 Assessment of pigment lines. Single lines of pigmentation were allocated half a point; two additional points were allotted as the pigmentation extended beyond the resting pupil edge. Total $=2.5$ points

$\mathrm{CH}$ ), primarily for assessment of PK. The presence of distichiasis and IIPPMs was also recorded. Ocular and facial morphometrics were collected by the same observer (SM).

\section{Schirmer tear test 1}

The authors specifically inquired about an ophthalmic history of KCS and attempted to measure STT1 readings in every Pug; Pugs that did not tolerate STT1 measurement were excluded from the study. Inclusion in the study required that the Pug exhibited a moist ocular surface on ophthalmic examination. Obvious clinical signs of KCS (except for the presence of corneal pigmentation) were grounds for immediate exclusion, including one or more than one of the following: the presence of a dull ocular surface in the non-pigmented part of the cornea, presence of ulcerative keratitis, presence of mucous

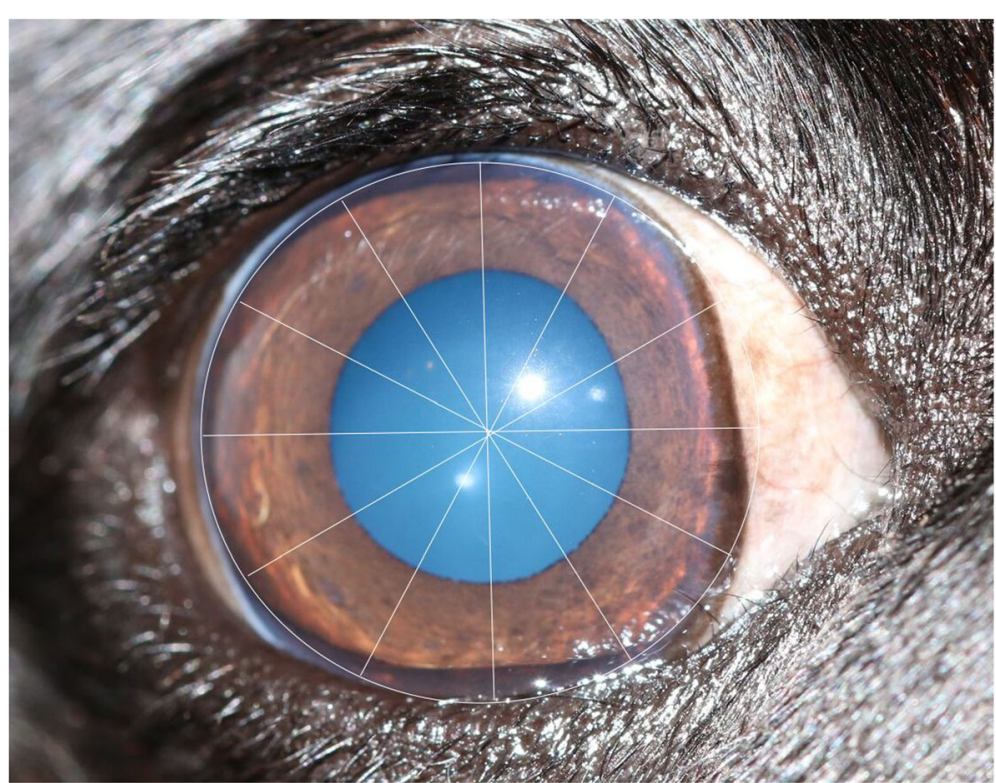

Fig. 5 Assessment of limbal brush border. Corneal pigmentation extends just beyond the limbus creating a 'limbal brush border' affecting three clock hours (3 points). Total $=3$ points 


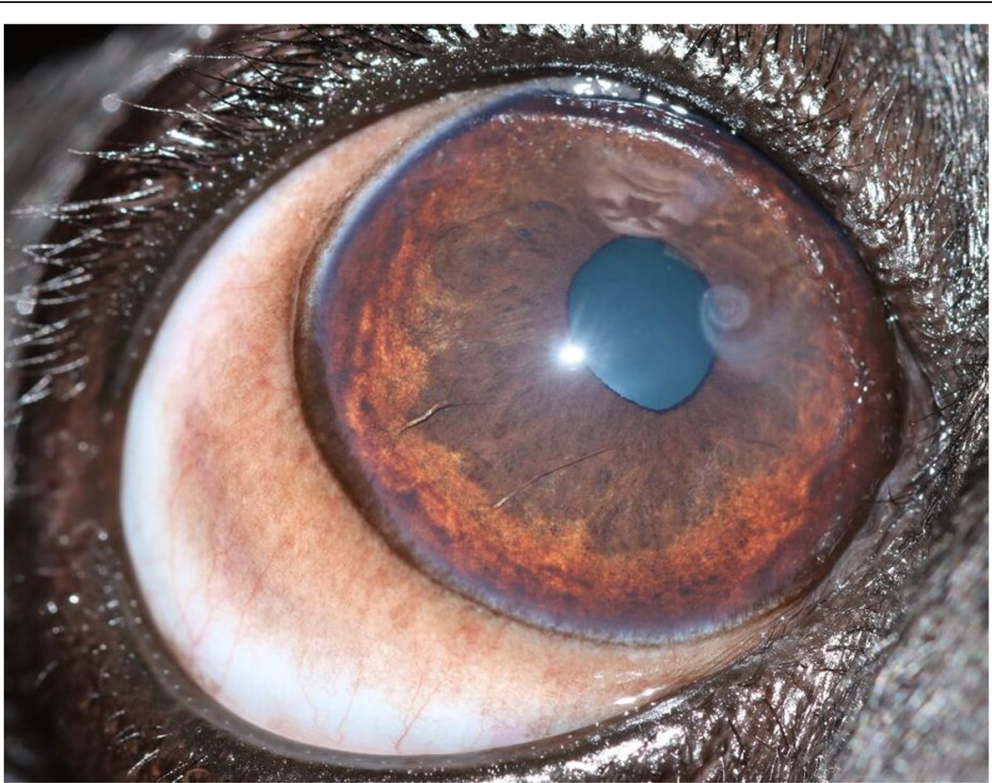

Fig. 6 Assessment of grey/white corneal lesions and swirls. The swirl was allotted points as though it represented corneal pigmentation; one point per clock hour plus an additional two points for encroaching upon the visual axis. Laterally, a limbal brush border affects two corneal clock hours (2 points). Total $=5$ points

discharge that adhered to the ocular surface and/or moderate, marked or severe conjunctival hyperaemia.

\section{Assessment of pigmentary keratitis}

A grading system for PK was developed by one of the authors (RS) for this study and was used for the assessment of all participants' eyes. The corneal surface was divided into 12 sectors or 'clock hours'. The extent of corneal pigmentation was assessed according to the number of 'clock hours' that were affected; one point was awarded per clock hour (Fig. 3). Single 'lines' of pigmentation were allocated a half-point (Fig. 4). One additional point was given if the pigmentation extended to the resting pupil edge; two additional points were assigned if the pigmentation extended beyond the resting pupil edge, encroaching upon the visual axis (Figs. 3 and 4). In cases where the corneal pigmentation extended only just beyond the limbus, this was termed a 'limbal brush border' and one point was allocated per clock hour affected (Fig. 5). Grey-white corneal lesions that presented medially and/or axially, often times with a centripetal 'swirl' appearance $[3,6]$, were considered a precursor to corneal pigmentation. These grey-white lesions were allotted points as though they represented corneal pigmentation i.e. one point was awarded per clock hour, with an additional 1-2 points if the swirl extended to or beyond the resting pupil edge (Fig. 6). The overall point score was then calculated and eyes were

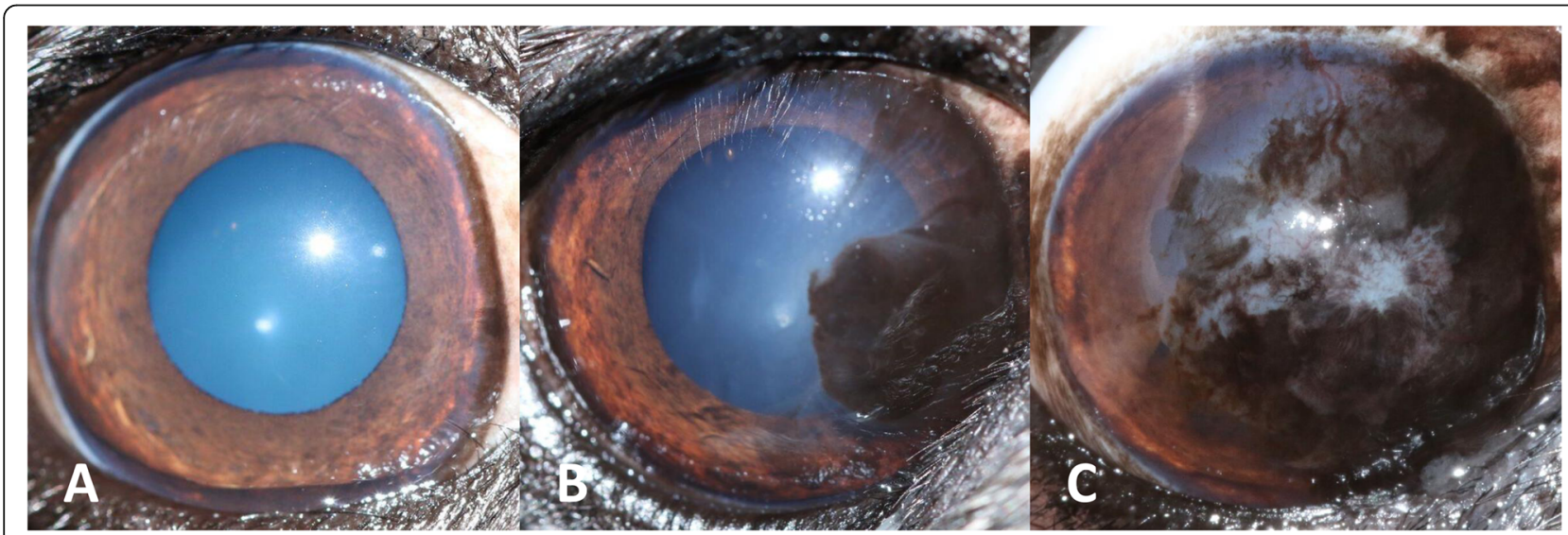

Fig. 7 Severity of PK. Examples of mild (a), moderate (b) and severe (c) PK 


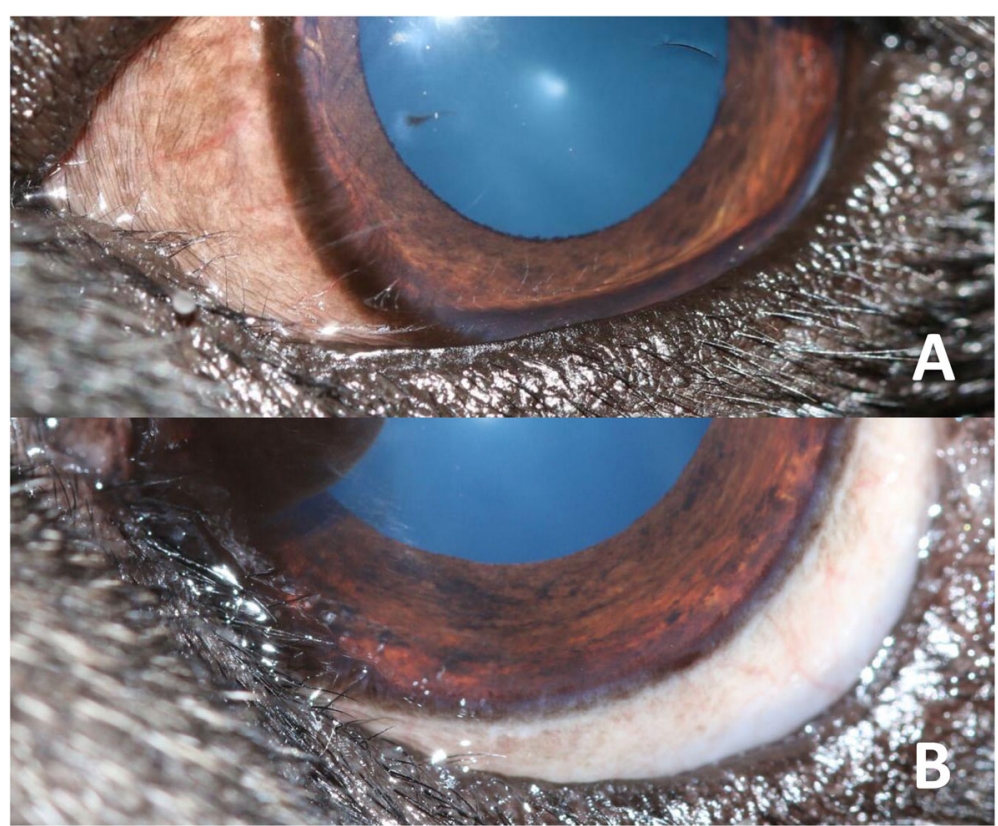

Fig. 8 Assessing length of MELE. Examples of 25\% lid length affected (a) and 33\% lid length affected (b)

assigned to one of three groups; mild (0.5-4.5 points), moderate (5.0-9.5 points) and severe (10.0-14.0 points) PK (Fig. 7).

\section{Assessment of MELE}

Three methods were used to record this data:

i) Presence or absence of MELE, which was recorded as a binary measure.

ii) Length of MELE. This was the proportion of eyelid length affected by MELE expressed as a percentage of lid length e.g. 25, 50\% (Fig. 8). Medial entropion of the upper eyelid was also recorded in this manner.

iii) Grade of MELE. This was the severity of MELE according to a scale devised for the study that included two grades. Grade 1 was assigned to MELE that had eyelid hairs in contact with the cornea predominantly pointing in one direction (medially or laterally). Grade 2 was assigned to MELE that had eyelid hairs which were in contact with the cornea and were crossing over each other to point in both directions (both medially and laterally) (Fig. 9).

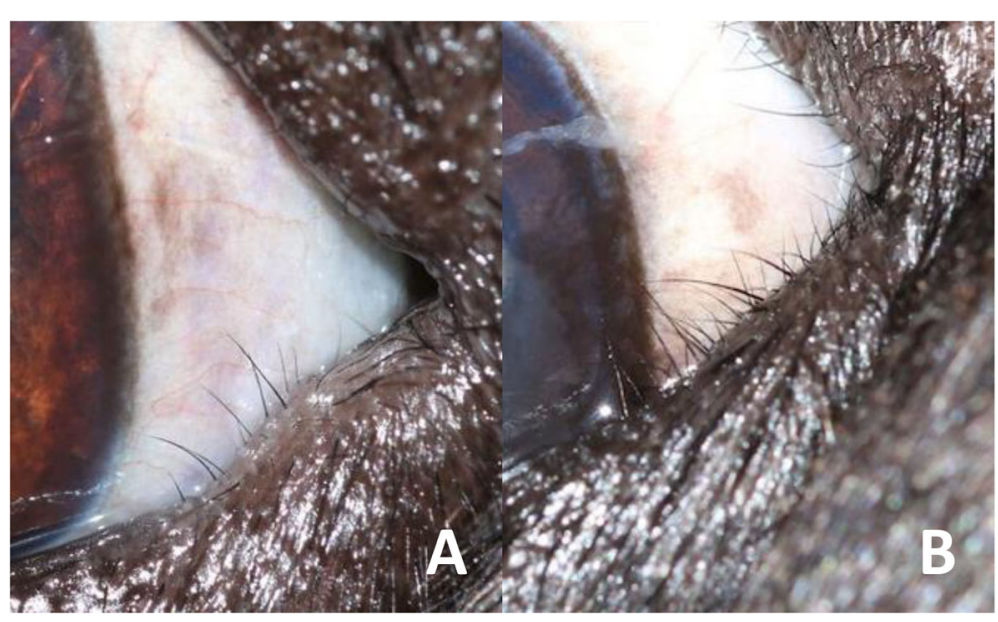

Fig. 9 Assessing grade of MELE. Examples of grade 1 (a) and grade 2 (b) MELE 


\section{Sample size calculation}

Optimal sample size was determined by performing a power calculation. A confidence level (CI) of $95 \%$ was selected, with $5 \%$ degree of precision and estimated prevalence of $82.4 \%$ (based on the results of a previous study [13]. Power analysis estimated the optimal sample size for this study to be 223 Pugs.

\section{Statistical analysis}

Percentage, mean $(+/-s d)$ and median (range) were used to summarise categorical and continuous variables. Age, STT1, MELE (\% length), MEUE (\% length), CFI, nasal fold width, palpebral fissure width and limbal pigmentation were analysed as continuous variables, whereas sex, neuter status, UK KC registration, coat colour, show dog status, ONW, IIPPMs and distichia were analysed as nominal variables and MELE (grade) as an ordinal variable. Repeated measure logistic regression (to account for correlation between the two eyes from the same pug) was used to assess association of predictors (the abovementioned signalment, breed club registration, ophthalmic, adnexal and facial findings) with detection and severity of PK. Predictors with $P \leq 0.10$ in the univariable analysis were included in the multivariable analysis, and backward elimination was used for model selection. Two-way interaction between predictors were assessed in the final multivariable model. Predictors with $P<0.05$ were considered significant. Odds ratio (OR) and its 95\% confidence intervals (CI) were reported. Statistical analyses were performed using IBM SPSS software (IBM SPSS Statistics for Macintosh, Version 24.0).

\section{Supplementary information}

Supplementary information accompanies this paper at https://doi.org/10. 1186/s12917-019-2127-y.

Additional file 1. Pigmentary keratitis in Pugs in the UK - Examination Form. Examination Record Form.

\section{Abbreviations}

CFI: Craniofacial index; IIPPMs: Iris-to-iris persistent pupillary membranes; KC: Kennel Club; KCS: Keratoconjunctivitis sicca; MELE: Medial entropion of the lower eyelid; MEUE: Medial entropion of the upper eyelid; ONW: Overnose-wrinkle; OR: Odds ratio; PK: Pigmentary keratitis; sd: Standard deviation; STT1: Schirmer tear test 1; UK: United Kingdom; USA: United States of America

\section{Acknowledgments}

We would like to acknowledge the following breed clubs, charities, institutions and individuals for their contribution to the study: The Kennel Club Charitable Trust, Wales \& West of England Pug Dog Club, Pug Dog Welfare \& Rescue Association, Pug Dog Club, West Pennine Pug Dog Club, Vet on the Hill' television show, Royal Veterinary College, Cynthia Timbury, Lynne Kellow, Sue Lee, Kelly Shackleton and Màrian Matas Riera.

\section{Authors' contributions}

SM (lead author) collaborated with RFS on the study design, ethics and grant applications. SM organised and coordinated attendance at social and breed club events for data collection. During data collection, SM performed facial and ocular measurements and recorded RFS/CH's examination findings. SM collaborated with YMC on statistical analysis. SM presented the findings at an international veterinary ophthalmology conference in the form of a conference abstract and PowerPoint presentation. SM wrote the manuscript, which was then reviewed and edited by the supervising authors and Coauthors; all co-authors read and gave their approval for publication of the final manuscript. RE attended most of the social and breed events and assisted with data collection and obtaining owner consent. RE reviewed and edited the conference abstract, international presentation and final manuscript. CD contributed to study design, attended most of the social and breed events and assisted with data collection and obtaining owner consent. CD reviewed and edited the conference abstract, international presentation and final manuscript. YMC provided support and guidance in performing statistical analysis both at the study design phase and following data collection. YMC reviewed and edited the conference abstract, international presentation and final manuscript. $\mathrm{CH}$ attended some of the social and breed events where she performed ophthalmic examinations and assisted with recording of examination findings. $\mathrm{CH}$ reviewed and edited the conference abstract, international presentation and final manuscript. RFS (supervising author) conceived the project and led the study design. RFS reviewed and contributed to the ethics and grant applications prior to their submission. RFS examined most of the pugs recruited to the study and assisted with recording of examination findings. RFS provided a seminar to owners and breeders, designed to increase awareness of the project and the disease process being researched. RFS reviewed and edited the conference abstract, international presentation and final manuscript. All authors read and approved the final manuscript.

\section{Funding}

A grant of $£ 4500$ was provided by The Kennel Club Charitable Trust. The funding body was not otherwise involved in the design of the study, collection, analysis and interpretation of data, or in writing the manuscript.

\section{Availability of data and materials}

The datasets used and/or analysed during the current study are available from the corresponding author on reasonable request.

\section{Ethics approval and consent to participate}

This project was approved by the Royal Veterinary College Ethics \& Welfare Committee on 18.04.2013 (Unique Reference Number 2013 1217). Informed, written consent was obtained from all participating owners.

\section{Consent for publication}

All data was anonymised for the purposes of analysis and publication. Owners were asked to sign a consent form for their pug to participate in the study; an additional consent form was signed for use of pet photographs for publicity, promotion, media, research and/education.

\section{Competing interests}

The authors declare that they have no competing interests.

\section{Author details}

'Langford Veterinary Services, University of Bristol, Langford, Bristol, UK. ${ }^{2}$ North Downs Specialist Referrals, Bletchingley, UK. ${ }^{3}$ The Royal Veterinary College, Ophthalmology Service, Department of Clinical Science and Services, University of London, North Mymms, Herts, UK. ${ }^{4}$ Research Office, The Royal Veterinary College, Camden Campus, London, UK. ${ }^{5}$ Ophthalmology Service, Specialistische Dierenkliniek Utrecht (part of Anicura), Utrecht, The Netherlands.

Received: 28 February 2019 Accepted: 1 October 2019

Published online: 30 October 2019

\section{References}

1. Vallone LV, Enders AM, Mohammed HO, Ledbetter EC. In vivo confocal microscopy of brachycephalic dogs with and without superficial corneal pigment. Vet Ophthalmol. 2016;20(4):294-303.

2. Azoulay T. Adjunctive cryotherapy for pigmentary keratitis in dogs: a study of 16 corneas. Vet Ophthalmol. 2013;17(4):241-9. 
3. Sanchez RF. The Cornea. In: Gould D, GJ ML, editors. BSAVA Manual of Canine and Feline Ophthalmology. 3rd ed. Gloucester: British Small Animal Veterinary Association. 2014; p. 200-31.

4. Bellhorn RW, Henkind P. Superficial pigmentary keratitis in the dog. JAVMA. 1966;149:173-5.

5. McCracken JS, Klintworth GK. Ultrastructural observations on experimentally produced melanin pigmentation of the corneal epithelium. Am J Pathol. 1976:85:167-82.

6. Kim S, Thomasy SM, Ramsey D, Zhao M, Mannis MJ, Murphy CJ. Whorl pattern keratopathies in veterinary and human patients. Vet Ophthalmol. 2018;21(6):661-7.

7. Slatter DH, Lavach JD, Severin GA, Young S. Uberreiter's syndrome (chronic superficial keratitis) in dogs in the Rocky Mountain area--a study of 463 cases. J Small Anim Pract. 1977;18(12):757-72.

8. Kaswan RL, Salisbury MA, Ward DA. Spontaneous canine Keratoconjunctivitis Sicca. Arch Ophthalmol. 1989;107:1210-6.

9. Yi NY, Park SA, Jeong MB, Kim MS, Lim JH, Nam TC, et al. Medial Canthoplasty for Epiphora in dogs: a retrospective study of 23 cases. J Am Anim Hosp Assoc. 2006;42(6):435-9.

10. Ledbetter EC, Marfurt CF, Dubielzig RR. Metaherpetic corneal disease in a dog associated with partial limbal stem cell deficiency and neurotrophic keratitis. Vet Ophthalmol. 2012:16(4):282-8

11. Krecny M, Tichy A, Rushton J, Nell B. A retrospective survey of ocular abnormalities in pugs: 130 cases. J Small Anim Pract. 2014;56(2):96-102.

12. Ledbetter EC, Gilger BC. Canine Ophthalmology. In: Gelatt KN, Gilger BC, Kern TJ, editors. Veterinary Ophthalmology. 5th ed. lowa: Wiley-Blackwell; 2018. p. 980-1. Corneal pigmentation; vol. 1.

13. Labelle AL, Dresser CB, Hamor RE, Allender MC, Disney JL. Characteristics of, prevalence of, and risk factors for corneal pigmentation (pigmentary keratopathy) in pugs. JAVMA. 2013;243(5):667-74.

14. van der Woerdt A. Adnexal surgery in dogs and cats. Vet Ophthalmol. 2004; 7(5):284-90.

15. Ledbetter EC, Gilger BC. Canine Ophthalmology. In: Gelatt KN, Gilger BC Kern TJ, editors. Veterinary Ophthalmology. 5th ed. lowa: Wiley-Blackwell; 2013. p. 010-2. Nonulcerative keratitis; vol. 1.

16. Nicholas E. The Cornea. In: Gray H, editor. Veterinary and Comparative Ophthalmology. London: H \& W Brown. 1914; pp. 161-163.

17. Sanchez RF, Daniels JT. Mini-review: Limbal stem cells deficiency in companion animals: time to give something Back? Curr Eye Res. 2015;41(4):425-32.

18. Allgoewer I, Sahr S, Neumann K. Abstracts: American College of Veterinary Ophthalmologists, Monterey, CA October 26-29, 2016. Abstract 75: Results of the evaluation of the long-term effect of different therapies on pigmentary keratitis (PK) of the Pug. Vet Ophthalmol. 2016;19(6):E21-43.

19. Steinmetz A, Markert C, Bernick J. Abstracts: Annual Scientific Meeting of the European College of Veterinary Ophthalmologists, Estoril, Portugal May 1821, 2017. Poster 48: Owner satisfaction after surgical therapy of the ocular brachycephalic syndrome - a survey. Vet Ophthalmol. 2017;20(4):E1-E14.

20. Packer R, Hendricks A, Burn CC. Do dog owners perceive the clinical signs related to conformational inherited disorders as "normal" for the breed? A potential constraint to improving canine welfare. Anim Welf. 2012;21(1):81-93.

21. Bernays ME, Flemming D, Peiffer RL. Primary corneal papilloma and squamous cell carcinoma associated with pigmentary keratitis in four dogs. JAVMA. 1999;214(2):215-7.

22. O'Neill DG, Lee MM, Brodbelt DC, Church DB, Sanchez RF. Corneal ulcerative disease in dogs under primary veterinary care in England: epidemiology and clinical management. Canine Genetics and Epidemiology 2017 4:1. Canine Genet Epidemiol. 2017;4(1):1-12.

23. Sutter NB, Mosher DS, Gray MM, Ostrander EA. Morphometrics within dog breeds are highly reproducible and dispute Rensch's rule. Mamm Genome Springer-Verlag. 2008;19(10-12):713-23.

\section{Publisher's Note}

Springer Nature remains neutral with regard to jurisdictional claims in published maps and institutional affiliations.

\section{Ready to submit your research? Choose BMC and benefit from:}

- fast, convenient online submission

- thorough peer review by experienced researchers in your field

- rapid publication on acceptance

- support for research data, including large and complex data types

- gold Open Access which fosters wider collaboration and increased citations

- maximum visibility for your research: over $100 \mathrm{M}$ website views per year

At BMC, research is always in progress.

Learn more biomedcentral.com/submissions 